\title{
THE STATE AND HUMAN RIGHTS: THE PROBLEMS OF RESTRICTIONS IN THE PANDEMIC
}

\author{
Lyubov A. Pozharova \\ Belgorod State National Research University, Belgorod, Russian Federation \\ Natalia A. Kosolapova \\ Belgorod State National Research University, Belgorod, Russian Federation
}

Introduction: in the context of modern life related to the fight against the COVID-19 pandemic, human rights and their implementation whose main goal is the existence of important social, economic and political relations are forced to be limited by the state. In this regard, the authors of the paper aim to analyze the problems that arise when the state interferes with the private sphere, and suggest the solutions that can serve as the additional guarantees of the full exercise of their rights by citizens. Methods: when writing the paper, the provisions of dialectical materialism and such methods as deduction and induction, analysis and synthesis, system, logical and other general scientific methods were used. Results: as a result of the analysis of the prevailing political and environmental conditions, it is possible to state that in an emergency situation, people often mistakenly perceive measures coming from the state as restrictions on their rights, which causes them to feel insecure and vulnerable. This may exacerbate a pre-existing sense of discrimination and inequality among certain social groups that require special economic and social support from the state. The research focuses on the problem of creating the necessary conditions for the state to ensure that individuals exercise and protect their rights without putting their lives and health at risk. The authors also consider the aspects related to citizens' access to participation in solving socially significant issues of public administration. Conclusions: as a result of the research, the main problems that arise from the state's restricting the rights in the pandemic are considered, as well as possible solutions that allow the state to effectively ensure stability in society, guaranteeing the implementation of basic human and civil rights and freedoms, and creating equal and stable social relations.

Key words: human and civil rights and freedoms, state, restriction of rights, legal restriction of rights and freedoms, security.

Citation. Pozharova L.A., Kosolapova N.A. The State and Human Rights: The Problems of Restrictions in the Pandemic. Legal Concept, 2020, vol. 19, no. 3, pp. 41-46. (in Russian). DOI: https://doi.org/10.15688/lc.jvolsu.2020.3.5

\section{ГОСУДАРСТВО И ПРАВА ЧЕЛОВЕКА: ПРОБЛЕМЫ ОГРАНИЧЕНИЙ В УСЛОВИЯХ ПАНДЕМИИ}

\author{
Любовь Анатольевна Пожарова \\ Белгородский государственный национальный исследовательский университет, \\ г. Белгород, Российская Федерация
}

Наталья Александровна Косолапова

Белгородский государственный национальный исследовательский университет, г. Белгород, Российская Федерация

Введение: в условиях современной действительности, связанной с борьбой с пандемией COVID-19, права человека и их реализация, главной целью которой является существование важных социальных, 
экономических и политических отношений, вынужденно ограничиваются государством. В связи с этим авторами статьи поставлена цель проанализировать проблемы, возникающие при вмешательстве государства в частную сферу, и предложить пути решения, которые могут выступить в качестве дополнительных гарантий реализации своих прав гражданами в полном объеме. Методы: в процессе написания статьи использовались положения диалектического материализма и такие методы, как дедукция и индукция, анализ и синтез, системный, логический и другие общенаучные методы. Результаты: в результате анализа сложившихся политических и экологических условий представляется возможным констатировать, что в чрезвычайной ситуации люди часто ошибочно воспринимают меры, исходящие от государства, как ограничения своих прав, что вызывает у них чувство незащищенности и уязвимости. Это может обострить ранее существовавшее ощущение дискриминации и неравенства у некоторых социальных групп населения, требующих особой экономической и социальной поддержки государства. Исследовательский акцент сделан на проблеме создания государством необходимых условий для обеспечения лицам реализации и защиты своих прав, не подвергая их жизни и здоровье риску. Также авторы рассматривают аспекты, связанные с доступом граждан к участию в решении социально значимых вопросов государственного управления. Выводы: в результате исследования рассмотрены основные проблемы, возникающие при ограничении прав государством в условиях пандемии, а также приводятся возможные пути решения, позволяющие государству эффективно обеспечить стабильность в обществе, гарантируя реализацию основных прав и свобод человека и гражданина, создавая равноправные и устойчивые общественные отношения.

Ключевые слова: права и свободы человека и гражданина, государство, ограничение прав, правовое ограничение прав и свобод, безопасность.

Цитирование. Пожарова Л. А., Косолапова Н. А. Государство и права человека: проблемы ограничений в условиях пандемии // Legal Concept = Правовая парадигма. - 2020. - T. 19, № 3. - C. 41-46. - DOI: https:// doi.org/10.15688/lc.jvolsu.2020.3.5

\section{Введение}

Социально-экономический кризис, отчетливо проявивший себя в процессе противодействия многих государств мира новой коронавирусной инфекции, показал, что вопросы реализации, связанные с правами человека, в настоящее время ставятся очень остро. Ситуации таких ограничений прав не могли не коснуться и России, и их решения должны естественным образом соответствовать высокому уровню общественного морального сознания и обеспечивать необходимую защиту в случае реальной угрозы.

В подобных ситуациях, сопровождающихся повышенной социальной напряженностью, государство должно минимизировать неорганизованность, спонтанность принятия решений. На нем лежит ответственность за формирование у общества чувства уверенности в завтрашнем дне, понимания необходимости применяемых мер и «формирования законодательных норм, которые порождают ценное чувство уверенности людей в будущем, многократном воспроизведении форм жизни, к которым они привыкли и которые высоко ценят» [3, с. 22].
Точное и правильное определение и закрепление полномочий между органами государственной власти будет способствовать установлению институциональной толерантности, гарантируя обеспечение прав и свобод человека и гражданина, а также оптимизирует социальную эффективность и улучшит функционирование самой системы, основными элементами правового воздействия на общественные отношения которой выступают правотворческие и правоприменительные акты.

\section{Проблемы ограничения прав, связанные с государственными мерами профилактики распространения коронавирусной инфекции}

По общему мнению роль и значение права в жизни общества на фоне современных реалий должны только возрастать. В то же время для реального положительного эффекта нововведений необходимо, чтобы «граждане выступали бы как равноправный партнер, участвующий в принятии важнейших решений, осуществляющий в предусмотренных законом формах контроль за деятельностью властных структур» [5, с. 19]. Правовое регулирование 
должно расширить гарантии в области прав человека и основных прав и свобод, предоставляемых государством в процессе влияния на общественные отношения путем приведения поведения участников этих отношений в соответствие с юридическими требованиями, представленными в законе. Легитимность таких требований должна поддерживаться обществом и обеспечиваться возможностью государства применять свою властную силу. В собственном понимании правового регулирования заключается функция государственного управления, принадлежащая исключительно государству, которое является гарантом права и при этом обладает монополией на правоприменительную и правоохранительную деятельность [6, с. 122].

Права и свободы человека и гражданина являются высшей ценностью, поэтому очень важно, чтобы в условиях пандемии государство особенно поддерживало механизмы, которые будут гарантировать основные социальные и экономические права, не ограничивая при этом выражение гражданских и политических прав [8, с. 94].

Полагаем, Российской Федерации полезно принять во внимание практику западноевропейских государств, предоставляющих возможность любому гражданину участвовать в обсуждении социально значимых вопросов и решений государственных органов, используя доступные средства выхода в Интернет (ноутбуки, компьютеры, мобильные телефоны и т. п.). Данный метод демократизации управления будет учитывать общественное настроение, выявляя таким образом вопросы, которые могут привести к острому несогласию и, как следствие, недовольству населения и беспорядкам. Но для этого необходимо найти соответствующие формы для закрепления таких форумов на законодательном уровне. Привлечение населения к обсуждению решений государственных органов по социальным вопросам (здравоохранение, экология, безопасность и т. п.), став обязанностью государства, подарит инициативу всем участникам публично-правовой сферы.

В условиях сложной эпидемиологической ситуации граждане не могут в полной мере реализовать свои права традиционными и привычными способами развития форм охраны прав и свобод, такими, например, как проведение собраний, митингов, демонстраций, шествий и пикетирований, но у них есть возможность «не остаться в стороне» и обозначить свою позицию посредством сети Интернет.

Особое внимание социальное государство должно уделять защите уязвимых лиц [2, с. 68], таких как пожилые люди, дети, инвалиды и мигранты. Использование информационных ресурсов в обсуждении вопросов социального значения позволит создать такую ситуацию, чтобы осуществление вышеупомянутых прав было гарантировано без дискриминации какой-либо социальной группы населения.

Цифровизация как простой метод улучшения разных частных сторон общественной жизни превратилась в одно из важных условий мирового общественного развития, обеспечивающих улучшение качества жизни [7, c. 47]. Заметим, что в период цифровизации общества, увеличения каналов связи и доступности источников информации социальные сети и средства массовой информации активно вмешиваются в частную жизнь людей, формируя общественное мнение и создавая определенные эталоны поведения для широких слоев населения. Однако наряду с положительными явлениями, пришедшими с цифровизацией, существуют и негативные, например, скрываясь за экраном монитора, некоторые лица позволяют себе оскорбительные и унижающие честь и достоинство другого пользователя комментарии, в том числе распространяют о личности недостоверную информацию дискредитирующего характера, используют кибербуллинг.

Политика государства в сфере правовой защиты человека от злоупотребления свободой слова и массовой информации находится на пути формирования. Мы разделяем точку зрения О.В. Власовой, что «именно достоинство человека должно выступать как критерий допустимости ограничения основных прав с целью предотвращения злоупотребления правом» [1, с. 17]. Современные средства массовой информации могут легко превратиться из инструмента защиты достоинства в источник угрозы. Чтобы этого не произошло, требуется разработка ряда дефиниций, устранение различного толкования правовых поня- 
тий, юридических коллизий, приведение в соответствие с международными и конституционными принципами законодательных норм.

Не игнорируя интересы граждан и привлекая их к обсуждению вопросов государственного управления, государство не создает ситуации и ощущения ограничения прав, что поможет не усугубить существующие заблуждения, предрассудки, неравенство или структурные барьеры и не приведет к росту насилия и дискриминации, особенно в отношении социально уязвимых лиц.

В случае невозможности использования ресурсов сети Интернет для участия граждан в реализации своих прав задачей государства должно стать создание таких условий, при которых физическое присутствие волеизъявителя не будет подвергнуто риску, связанному со сложившейся чрезвычайной ситуацией в области общественного здравоохранения. Примером может послужить проведение Общероссийского голосования по вопросу одобрения изменений в Конституцию Российской Федерации с соблюдением рекомендательных мер по профилактике рисков, связанных с распространением коронавирусной инфекции [4].

Нынешний кризис общественного здравоохранения, вызванный распространением коронавирусной инфекции, является чрезвычайной ситуацией для всех стран и приводит к продолжительным социальным, экономическим, политическим и экологическим последствиям для всего населения земного шара. В то же время можно наблюдать очевидные и растущие свидетельства того, что ответные меры государства при оказании медицинской помощи, осуществлении мер по снижению распространения COVID-19 и политики ограничений, направленных на смягчение экономических последствий, оказывают несоразмерное и неправомерное воздействие на население, особенно на отдельные его группы. Пандемия разоблачает и углубляет существующую дискриминацию, насилие и другие нарушения прав человека, поэтому государству необходимо выступить гарантом прав и свобод человека и реагировать таким образом, чтобы принятые решения находили поддержку граждан и были направлены на их защиту.
Пути решения негативных социальных последствий, связанных с ограничением прав граждан

Одной из главных задач социального государства является поиск баланса между частными и публичными интересами, поиск оптимальных компромиссных решений и нивелирование негативных последствий при невозможности учета интереса обеих сторон.

Нарушение или несоблюдение государством основных прав и свобод человека и гражданина, отсутствие чувства безопасности в обществе может спровоцировать правовую неуверенность граждан в защите и возможности обеспечить правопорядок со стороны государства, что приводит к подрыву авторитета власти в целом. В ситуации страха за свою жизнь и безопасность, не находя поддержки от государства, человек перестает ценить и уважать силу правовых актов, переходя к неправовым способам защиты, приводящим, как правило, к актам агрессии и насилию.

Поэтому предельно важно государственным органам проводить дополнительные разъяснения, давать консультации по принятым решениям, касающимся разного рода ограничений, направленных на обеспечение безопасности жизни и здоровья населения.

Здесь и возникает важность создания равных перед законом возможностей доступа граждан к социальным благам, возникновения обязанностей и ответственности личности и государства, участия в обсуждении важных вопросов и решений.

\section{Выводы}

Признавая, что действия по борьбе с пандемией COVID-19 являются срочными и необходимыми, государство должно обеспечивать соблюдение международных и национальных обязательств в области прав человека в ответ на возникшие обстоятельства, а также принимать во внимание уязвимость конкретных групп населения, включая инвалидов, пожилых людей, иммигрантов и лиц без гражданства. Для достижения этой цели разработка, реализация и оценка мер, принимаемых государством, должны проводиться с участием граждан и обще- 
ственных объединений, представляющих интересы отдельных социальных групп.

Полагаем, что для преодоления данного кризиса необходимо, чтобы государственные органы сохраняли «прозрачность» в своей работе, выполняли возложенные на них обязательства, предоставляли возможность подлинного участия граждан в жизни страны и гарантировали реализацию прав и свобод человека и гражданина.

\section{СПИСОК ЛИТЕРАТУРЫ}

1. Власова, О. В. Достоинство человека как нравственно-правовая ценность: общетеоретическое исследование : автореф. дис. ... д-ра юрид. наук : 12.00.01 / Власова Оксана Вячеславовна. - Саратов, 2011. $-54 \mathrm{c}$.

2. Кочеткова, Л. Н. Социальное государство: цели и функции / Л. Н. Кочеткова // Социально-гуманитарные знания. - 2008. - № 3. - С. 68-79.

3. Мальцев, Г. В. Социальные основания права : монография / Г. В. Мальцев. - М. : Норма : ИНФРА-М, 2011. - 800 c.

4. Рекомендации по профилактике рисков, связанных с распространением коронавирусной инфекции (COVID-19). - Электрон. дан. - Режим доступа: http://www.cikrf.ru/analog/constitutionvoting/profilaktika/ (дата обращения: 17.06.2020). Загл. с экрана.

5. Смоленский, М. Б. Правовая культура и идея государственности / М. Б. Смоленский // Государство и право. -2009 . - № 4. - С. 15-21.

6. Тирских, М. Г. Особенности правового регулирования как элемента государственного управления / М. Г. Тирских // Сибирский юридический вестник. - 2013. - № 1 (60). - С. 122-126.

7. Халин, В. Г. Цифровизация и ее влияние на российскую экономику и ее преимущества, вызовы, угрозы и риски / В. Г. Халин, Г. В. Чернова // Управленческое консультирование. - 2018. - № 10. C. $46-63$.

8. Хозикова, Е. С. Правовое государство и гарантии обеспечения прав и свобод человека и гражданина в Российской Федерации / Е. С. Хозикова // Юридическая наука и правоохранительная практика. -2012. - № 3 (21). - С. 94-99.

\section{REFERENCES}

1. Vlasova O.V. Dostoinstvo cheloveka kak nravstvenno-pravovaya tsennost: obshcheteoreticheskoe issledovanie: avtoref. dis. ... d-ra yurid. nauk: 12.00.01 [Human Dignity as Moral and Legal Value: General Theoretical Research. Dr. jurid. sci. abs. diss.]. Saratov, 2011.54 p.

2. Kochetkova L.N. Sotsialnoe gosudarstvo: tseli i funktsii [The Social State: Objectives and Functions]. Sotsialno-gumanitarnye znaniya [Social and Humanitarian Knowledge], 2008, no. 3, pp. 68-79.

3. Malcev G.V. Socialnye osnovaniya prava: monografiya [Social Foundations of Law. Monograph]. Moscow, Norma, Infra-M Publ., 2011. 800 p.

4. Rekomendatsii po profilaktike riskov, svyazannykh s rasprostraneniem koronavirusnoy infektsii (COVID-19) [Recommendations for Preventing Risks Associated with the Spread of Coronavirus Infection (COVID-19)]. URL: http:// www.cikrf.ru/analog/constitution-voting/profilaktika/ (accessed 17 June 2020).

5. Smolenskij M.B. Pravovaya kultura i ideya gosudarstvennosti [Legal Culture and the Idea of Statehood]. Gosudarstvo i pravo [The State and the Law], 2009, no. 4, pp. 15-21.

6. Tirskih M.G. Osobennosti pravovogo regulirovaniya kak elementa gosudarstvennogo upravleniya [The Features of Legal Regulation as an Element of Public Administration]. Sibirskiy yuridicheskiy vestnik [Siberian Law Review], 2013, no. 1 (60), pp. 122-126.

7. Halin V.G., Chernova G.V. Tsifrovizatsiya i ee vliyanie na rossiyskuyu ekonomiku i ee preimushchestva, vyzovy, ugrozy i riski [Digitalization and Its Impact on the Russian Economy and Its Advantages, Challenges, Threats and Risks]. Upravlencheskoe konsultirovanie [The Management Consulting], 2018, no. 10, pp. 46-63.

8. Hozikova E.S. Pravovoe gosudarstvo i garantii obespecheniya prav i svobod cheloveka i grazhdanina v Rossiyskoy Federatsii [The Legal State and Guarantees to Ensure the Rights and Freedoms of a Human and Citizen in the Russian Federation]. Yuridicheskaya nauka i pravookhranitelnaya praktika [The Legal Science and Law Enforcement Practice], 2012, no. 3 (21), pp. 94-99. 


\section{Information About the Authors}

Lyubov A. Pozharova, Candidate of Sciences (Jurisprudence), Associate Professor, Department of Theory and History of State and Law, Belgorod State National Research University, Pobedy St, 85, 308015 Belgorod, Russian Federation, pozharova@bsu.edu.ru, https://orcid.org/0000-0001-5704-9807

Natalia A. Kosolapova, Candidate of Sciences (Jurisprudence), Associate Professor, Department of Theory and History of State and Law, Belgorod State National Research University, Pobedy St, 85, 308015 Belgorod, Russian Federation, kosolapova@bsu.edu.ru, https://orcid.org/0000-0003-3753-9387

\section{Информация об авторах}

Любовь Анатольевна Пожарова, кандидат юридических наук, доцент кафедры теории и истории государства и права, Белгородский государственный национальный исследовательский университет, ул. Победы, 85, 308015 г. Белгород, Российская Федерация, pozharova@ bsu.edu.ru, https://orcid.org/0000-0001-5704-9807

Наталья Александровна Косолапова, кандидат юридических наук, доцент кафедры теории и истории государства и права, Белгородский государственный национальный исследовательский университет, ул. Победы, 85, 308015 г. Белгород, Российская Федерация, kosolapova@bsu.edu.ru, https://orcid.org/0000-0003-3753-9387 